\title{
Contribution of Landsat TM Data for the Detection of Urban Heat Islands Areas Case of Casablanca
}

\author{
Hassan Rhinane, Atika Hilali, Hicham Bahi, Aziza Berrada \\ Faculty of Sciences Ain Chock, University Hassan II, Casablanca, Morocco \\ Email: \{h.rhinane, bahi.h88\}@gmail.com, a.hilali@fsac.ac.ma, berrada_aziza@yahoo.fr
}

Received August 28, 2011; revised October 13, 2011; accepted November 7, 2011

\begin{abstract}
Casablanca, main metropolis of Morocco concentrates more than $46 \%$ of the working population. She is considered as the most affected city by the increase of the temperature. We have therefore chosen to base our study on the city of Casablanca. The main objective of this study is to estimate the ground temperature in order to evaluate the impact of the vegetation on cooling the ground temperature. In order to move to the achievement and to identify the formation of islands of warmth or coolness which occur in the urban municipalities of Casablanca, we have used the satellites images Landsat $5 \mathrm{TM}$. Graphical analysis based on studying the correlation was performed to quantify the strength of the link between the coolest urban surfaces and the green spaces. To achieve this, we used "mono-window" algorithm which requires knowledge of the atmospheric transmittance, the emissivity of soil and the effective temperature of the air. This study revealed a strong correlation between vegetation cover and cold areas $\left(\mathrm{R}^{2}=0.911\right)$ and allowed us to determine graphically that there is a strong link between the urban ground temperature and the density of buildings.
\end{abstract}

Keywords: Urban Remote Sensing; Thematic Mapper; Heat Islands; Freshness Islands; Land Surface Temperature; Casablanca

\section{Introduction}

According to the prospective study "Morocco 2030" conducted by the Planning Department, Morocco will count ten million more urban residents (66\% of the population) [1]. The population growth in 2030 will be concentrated in the cities and in a higher proportion in the economical metropolis Casablanca and this in addition to a dense urban development.

The National Agency of meteorology, in collaboration with the World Bank, confirmed that the country will face a significant increase in room temperature, an increase of at least $1.6^{\circ} \mathrm{C}$ compared to the average room temperature, in the decades to come.

Zhanq and Wang (2008) studied the relationship between these two issues and found that there is a correlation between the formation of the heat island, population density and concentration of built [2]. Sébastien Gadal meanwhile showed the contribution of thermal infrared data, often used to estimate the land surface temperature, on the remote sensing of urban concentration and the residents [3]. In [4], it has been shown that information on land use can be derived directly from the land surface temperature. Others have suggested that changes in land use have significant effects on climate [5].

Therefore, from these studies it seems clear that the heat island effect in urban areas will be multiplied in the future because of several causes like as natural causes that are related to climatic and geographical problems, and other anthropogenic.

This represents an additional challenge not only on the deterioration of the climate and the quality of the area but also the emergence of problems related to public health.

This article focuses on the identification of areas affected by urban heat islands at each town in Casablanca to study the role of vegetation in controlling this phenomenon.

\section{Material and Methods}

\subsection{Location of the Study}

Casablanca, Morocco's economic capital is located on the Atlantic coast (Lat $33^{\circ} 36^{\prime} \mathrm{N}$, Long $07^{\circ} 36^{\prime} \mathrm{W}$ ). The Casablanca region has nearly 4 million inhabitants extending to $1615 \mathrm{~km}^{2}$ which is the most populous city in North Africa and one of the largest cities in the continent. Its average temperatures are $12^{\circ} \mathrm{C}$ in winter and $25^{\circ} \mathrm{C}$ in summer with a temperate and humid climate. The high average annual precipitation is $400 \mathrm{~mm}$.

The study area has warmed in recent decades. Annually, the average temperature has increased over the period 1961-2008, with a trend of $0.3^{\circ} \mathrm{C}$ per decade in Casablanca [6]. In terms of rainfall, the Moroccan cities show 
a clear downward trend with a decline of about $2.8 \mathrm{~mm} /$ year [6] (See Figure 1).

\subsection{Materials/Data}

Satellite images are the important source of data to obtain information about the Earth's surface without direct contact.

To identify thermal anomalies we used a scene from Landsat 5 TM (Thematic Mapper) acquired on 08/01/2011 at 10:53. The Landsat image is projected in UTM (Universal Transverse Mercator) with a resolution of 30 meters for all bands.

The air temperature and humidity were obtained on the weather sites [7].

The following table (Table 1) shows the different characteristics of the TM image.

\subsection{Methods}

The Figure 2 shows the logical sequence for the recovery of urban surface temperature used in this study.

As it will be mentioned in the following sections this process will be divided in three main parts:

The first part consists of estimating the emissivity of soil from the NDVI.

The second part will allow us to calculate the brightness temperature, also known as the temperature of surface marked at the sensor, depending on the spectral radiance (greatness obtained by performing a radiometric correction of the thermal-infrared band). The brightness temperature requires knowledge of some parameters such as constants of calibration $\mathrm{K}_{1}$ and $\mathrm{K}_{2}$ which are given by the manufacturer of the sensor.

In the third part we will use the Mono-Window algorithm [2] to recover the land surface temperatures by considering the action of the atmosphere, this greatness can be calculated from the parameters obtained in the first and the second part, it also requires knowledge of additional parameters such as effective temperature and atmospheric transmittance, which can be estimated from meteorological data.
The heat islands area and islets of freshness were extracted from the land surface temperature by using a segmentation method based on calculating the arithmetic mean and the standard deviation.

More details will be presented in the following paragraphs.

\subsubsection{Estimation of NDVI}

In remote sensing, the term vegetation refers to chlorophyll, several indices have been developed to analyze the abundance of vegetation, and they are based on a report of the red band which is related to the absorption of light by chlorophyll and near-infrared that is related to the density of green vegetation. The index more used is the NDVI index (Normalized Difference Vegetation Index) that is considered among the best known indices and widely used to study and map the plants. Dengsheng Lu and Jacquelyn Schubring [8] have used this index to estimate the abundance of vegetation and study her relationship with surface temperature [8]. Others have used it to study the impact of rainfall on the abundance of vegetation [9].

Several researchers have used other vegetation indices as TSARVI (Transformed Soil Atmospherically Resistant Vegetation Index) to improve the classification accuracy for thematic mapping in heterogeneous media [10].

The normalized difference vegetation index for Landsat $5 \mathrm{TM}$ results in the following formula:

$$
\mathrm{NDVI}=\frac{\mathrm{TM}[4]-\mathrm{TM}[4]}{\mathrm{TM}[4]+\mathrm{TM}[3]}
$$

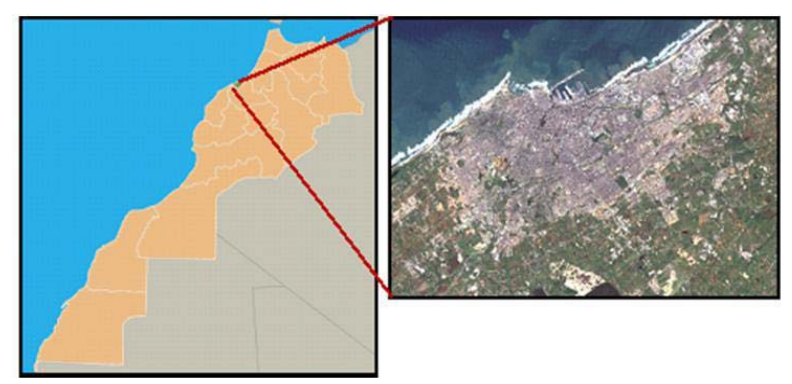

Figure 1. The study area location.

Table 1. Technical data of the sensor Landsat 5 TM.

\begin{tabular}{|c|c|c|c|c|c|c|}
\hline Bands of the TM & $\begin{array}{c}\text { Spectral } \\
\text { Resolution }(\mu \mathrm{m})\end{array}$ & $\begin{array}{c}\text { Spatial } \\
\text { Resolution (m) }\end{array}$ & Color & Field width (KM) & $\begin{array}{c}\text { Time of Equator } \\
\text { crossing }\end{array}$ & $\begin{array}{l}\text { Orbital } \\
\text { altitude }\end{array}$ \\
\hline $\mathrm{TM}[1]$ & $0.45-0.52$ & $30 * 30$ & Blue & & & \\
\hline TM [2] & $0.52-0.60$ & $30 * 30$ & Green & & & \\
\hline TM [3] & $0.63-0.69$ & $30 * 30$ & Red & & & \\
\hline TM [4] & $0.76-0.90$ & $30 * 30$ & NIR & 185 & 16 days & $710 \mathrm{Km}$ \\
\hline $\mathrm{TM}[5]$ & $1.55-1.75$ & $30 * 30$ & Mid-IR & & & \\
\hline TM [6] & $10.4-12.5$ & $30 * 30$ & Thermal IR & & & \\
\hline TM [7] & $2.08-2.35$ & $30 * 30$ & Mid-IR & & & \\
\hline
\end{tabular}




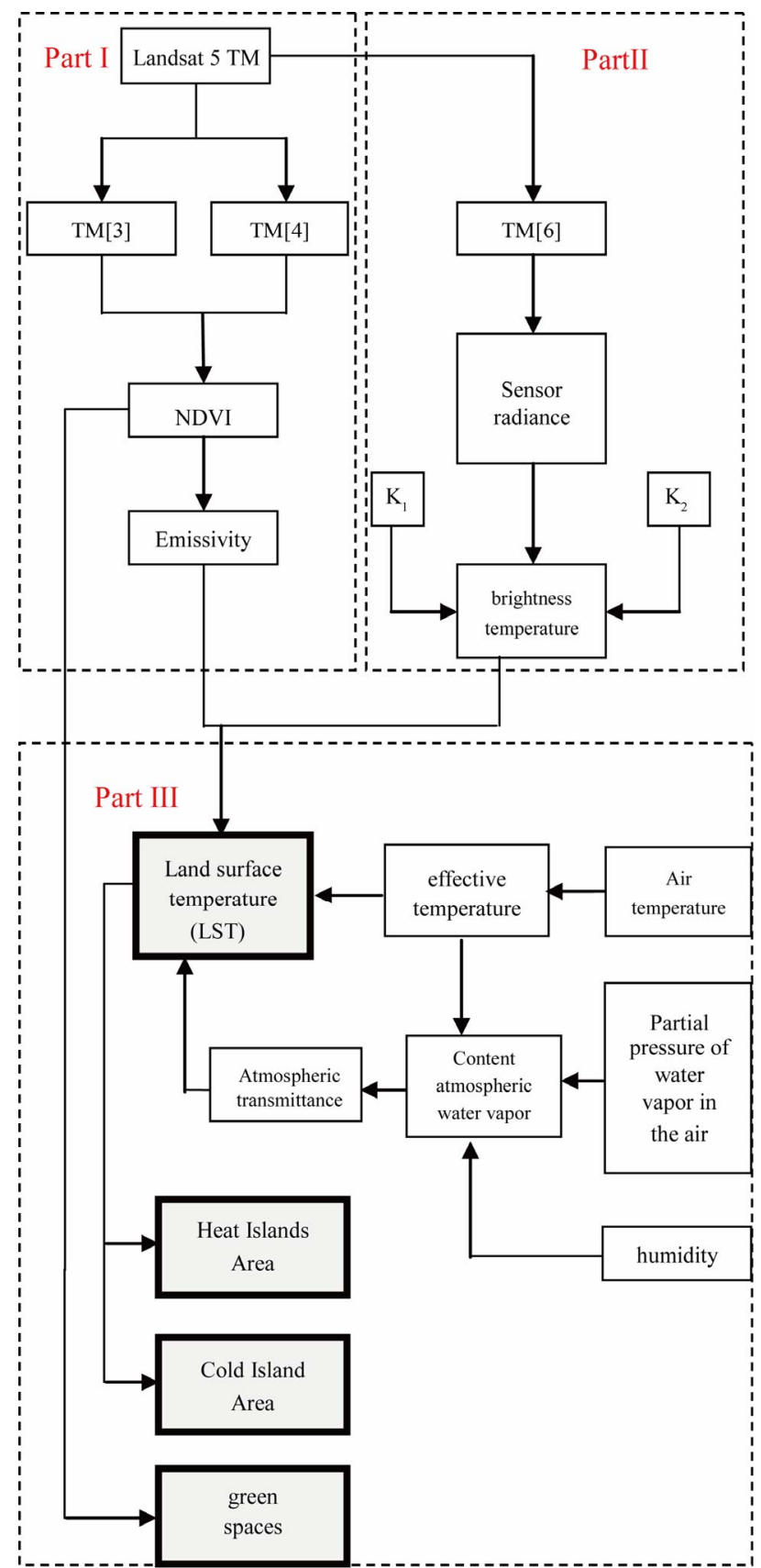

Figure 2. The processing used for estimating the urban surface temperature.

\subsubsection{Estimation of Ground Surface Emissivity}

The emissivity is radiative properties of objects. It characterizes the ability of a body to emit radiation. There are two methods to estimate the emissivity of the soil, the first is to select the training data of materials classes and affect the value of the emissivity appropriate to each class, and the second is to estimate the emissivity by exploiting a statistical relationship that binds it to the vegetation index.

According to [11], this linear relationship is written as follows:

$$
\varepsilon=1.0094+0.047 \mathrm{Ln}(\mathrm{NDVI})
$$

when the value of the NDVI ranges from 0.157 to 0.727 .

Another method has been developed [10] to estimate the emissivity from the NDVI, as follows:

$$
\varepsilon=\varepsilon_{\mathrm{v}} \mathrm{P}_{\mathrm{v}}+\varepsilon_{\mathrm{s}}\left(1-\mathrm{P}_{\mathrm{v}}\right)+\mathrm{d} \varepsilon
$$

where

$\varepsilon_{\mathrm{v}}$ is the vegetation emissivity

$\varepsilon_{\mathrm{s}}$ is the soil emissivity

$\mathrm{P}_{\mathrm{v}}$ is the vegetation proportion, witch can be estimated by the following equation:

$$
P_{v}=\left[\frac{N D V I-N D V I_{\text {min }}}{N D V I_{\text {max }}-N_{\text {NDI }} \text { min }}\right]^{2}
$$

with $\mathrm{NDVI}_{\text {min }}$ and $\mathrm{NDVI}_{\text {max }}$ correspond to 0.2 and 0.5 . d $\varepsilon$ represents the effect of the geometric distribution of surfaces. For plain surfaces that term is negligible but for heterogeneous and rough surfaces that term can reach a value of $2 \%$. A good estimate of this term can be given as follows:

$$
\mathrm{d} \varepsilon=\left(1-\varepsilon_{\mathrm{s}}\right)\left(1-\mathrm{P}_{\mathrm{v}}\right) \mathrm{F} \varepsilon_{\mathrm{v}}
$$

$\mathrm{F}$ : is a shape factor whose average value is 0.55 .

\subsubsection{Estimation of Land Surface Temperature}

The estimated temperature of the surface requires a processing and knowledge of several parameters. In this process an atmospheric correction is very useful to eliminate the action of the atmosphere and isolate the spectral signatures of terrestrial objects.

Thus, the first step is to convert numeric values to luminance (radiance). The following equation developed by National Aeronautics and Space Administration (NASA) is generally used to calculate the spectral radiance from the numerical values of the TM data:

$$
\mathrm{L}_{(\lambda)}=\mathrm{L}_{\min (\lambda)}+\left(\mathrm{L}_{\max (\lambda)}-\mathrm{L}_{\min (\lambda)}\right) \mathrm{Q}_{\mathrm{dn}} / \mathrm{Q}_{\max }
$$

$\mathrm{L}_{(\lambda)}$ : spectral radiance.

$\mathrm{Q}_{\mathrm{dn}}$ : the gray level of the TM image.

$\mathrm{Q}_{\max }$ : the maximum numerical value of the TM image.

$\mathrm{L}_{\min (\lambda)}$ and $\mathrm{L}_{\max (\lambda)}$ are respectively the minimum and maximum spectral radiance for $\mathrm{Q}_{\mathrm{dn}}=0$ and $\mathrm{Q}_{\mathrm{dn}}=255$.

The spectral radiance can be converted to a variable physically more useful, it is the brightness temperature corresponding to the apparent temperature of a surface measured at the sensor.

The formula for conversion is as follows [12]:

$$
\mathrm{T}_{\mathrm{sat}}=\frac{\mathrm{K}_{2}}{\operatorname{In}\left(\frac{\mathrm{K}_{1}}{\mathrm{~L}_{\lambda}}+1\right)}
$$

$\mathrm{T}_{\mathrm{sat}}$ is the brightness temperature. 
The coefficients $\mathrm{k}_{1}$ and $\mathrm{k}_{2}$ are the constants of calibration given by the manufacturer of the sensor, for TM sensors $\mathrm{K}_{1}$ and $\mathrm{K}_{2}$ are respectively equal to 607.76 watts/ (meter squared $*$ ster $* \mathrm{~m}$ ) and 1260.56 Kelvin.

This temperature is not the real temperature of the surface; it is the effective at-satellite temperature. To calculate the true temperature by considering the atmospheric effects we must apply an atmospheric correction.

Qin and Karnieli [13] have developed an algorithm, Mono-window, which allows apply this correction, witch requires knowledge of some parameters such as: the emissivity, atmospheric transmittance and the effective temperature [13]. low:

The expression of Mono-Window algorithm is as fol-

$$
\mathrm{T}_{\mathrm{s}}=\frac{\mathrm{a}(1-\mathrm{C}-\mathrm{D})+[\mathrm{b}(1-\mathrm{C}-\mathrm{D})] \mathrm{T}_{\mathrm{sat}}-\mathrm{DT}_{\mathrm{a}}}{\mathrm{C}}
$$

where $T_{\mathrm{s}}$ is the land surface temperature, $T_{\text {sat }}$ is the brightness temperature, $T_{a}$ is the effective temperature estimated from the air temperature, $\mathrm{a}$ and $\mathrm{b}$ are two constants equal respectively to -67.355351 and 0.458606 . C and $\mathrm{D}$ are two parameters that can be calculated using the following formulas:

$$
\begin{aligned}
& \mathrm{C}=\varepsilon \tau \\
& \mathrm{D}=(1-\tau)[1+(1-\mu) \tau]
\end{aligned}
$$

with $\varepsilon$ is the soil emissivity and $\tau$ is the atmospheric transmittance that can be estimated from the air temperature and the atmospheric content in water vapor.

The atmospheric content in water vapor can be derived according to the humidity $\phi_{\mathrm{r}}$ and the partial pressure of water vapor in the air $\mathrm{P}_{\mathrm{s}}$.

Leckner's formula mentioned in [14] allows as establishing this relationship:

$$
\mathrm{W}=\frac{0.493 \cdot \phi_{\mathrm{r}} \cdot \mathrm{P}_{\mathrm{s}}}{\mathrm{T}}
$$

The partial pressure of water vapor in the air is estimated as follow:

$$
P_{s}=e\left(26.23-\frac{5416}{T}\right)
$$

The only unknown parameter for the algorithm is the transmission factor. The mono-window algorithm allows us to establish a simple linear relationship to estimate the transmittance from water vapor as shown in the Table 2 below [15].

\subsubsection{Extraction of Freshness and Heat Islands Area}

The surface temperature at the urban municipalities of Casablanca is a variable parameter, and therefore the conventional segmentation method based on the arbitrary choice of the value of the threshold may not concretely extract the formations of the heat islands area related on each municipality.

[16] has developed another method which gives more credibility, this method based on calculating the arithmetic mean and standard deviation [16]. The equation developed by [16] is:

$$
\mathrm{T}=\mathrm{a} \pm \chi * \mathrm{~S}
$$

where "a" represents the mean temperature, $\mathrm{S}$ is the standard deviation and $\chi$ statistical series:

$$
\begin{gathered}
\chi=(-3,-2.5,-2,-1.5,-1,-0.5,0,0.5,1,1.5,2,2.5,3, \\
3.5,4)
\end{gathered}
$$

The principle of the method of [16] is to calculate values for thresholding for each element of the statistical series, and subdivided the urban surface temperature by interval considering the values of thresholding as limit and make a graph to quantify the appropriate temperatures at each interval. In this study more than $75 \%$ of the luminance values were marked between the two temperatures that are for $\chi$ respectively -1 and 1 .

So the thresholding value $(a+S)$ will be used to extract the heat islands area, while $(\mathrm{a}-\mathrm{S})$ will be used to identify urban surfaces fresh.

\section{Results and Discussions}

\section{Retrieved LST and HIA for Each Municipalities of Casablanca}

The temperature of the urban area of the city of Casablanca, shown in Figure 3, estimated from Landsat 5 TM data ranges from 286.01 Kelvin to 316.32 Kelvin, and the highest temperatures are marked in areas known as density built, and particularly in industrial areas and slums with a temperature exceeding 302.5 K (Figure 4), while the lowest temperatures are marked in villas zones and green areas with a temperature less than 293 Kelvin (Figure 5).

Areas shaded in red correspond to the sectors particularly affected by heat islands, the blue tinted reflect a significant presence of vegetation and water.

The photo interpretation of satellite images of Casablanca illustrates the concordance between the urban concentration and surface temperatures, and this is particularly true in municipalities known to a density contrast of built like the case of municipality of "ASSOUKHOUR ASSAWDA", "AL FIDA" and "HAY MOHAMMADI".

Table 2. Estimation of atmospheric transmittance.

\begin{tabular}{ccc}
\hline & Water vapor $\left(\mathbf{g} \cdot \mathbf{c m}^{-2}\right)$ & Transmittance equation \\
\hline $\begin{array}{c}\text { High air } \\
\text { temperature }\end{array}$ & $0.4-1.6$ & $\tau=0.974290-0.08007 \mathrm{~W}$ \\
$\begin{array}{c}\text { Low air } \\
\text { temperature }\end{array}$ & $1.6-3.0$ & $\tau=1.031412-0.11536 \mathrm{~W}$ \\
\hline
\end{tabular}




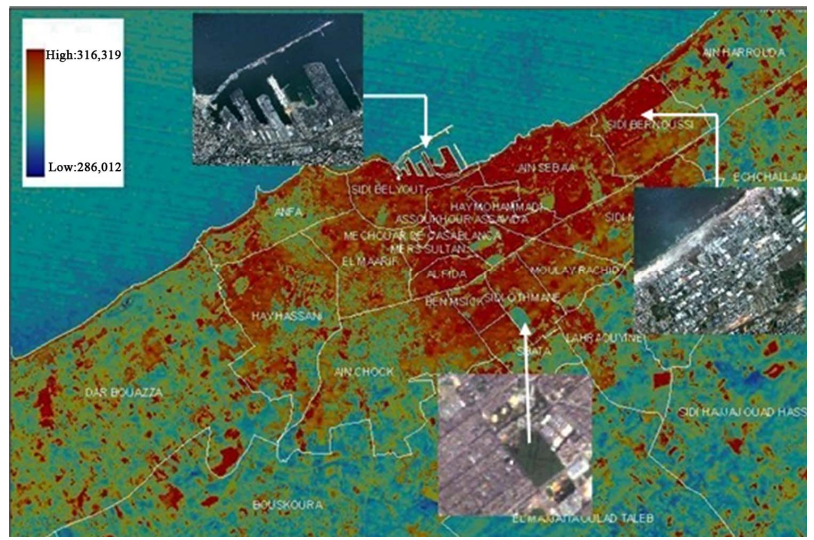

Figure 3. Land surface temperature of Casablanca in Kelvin.

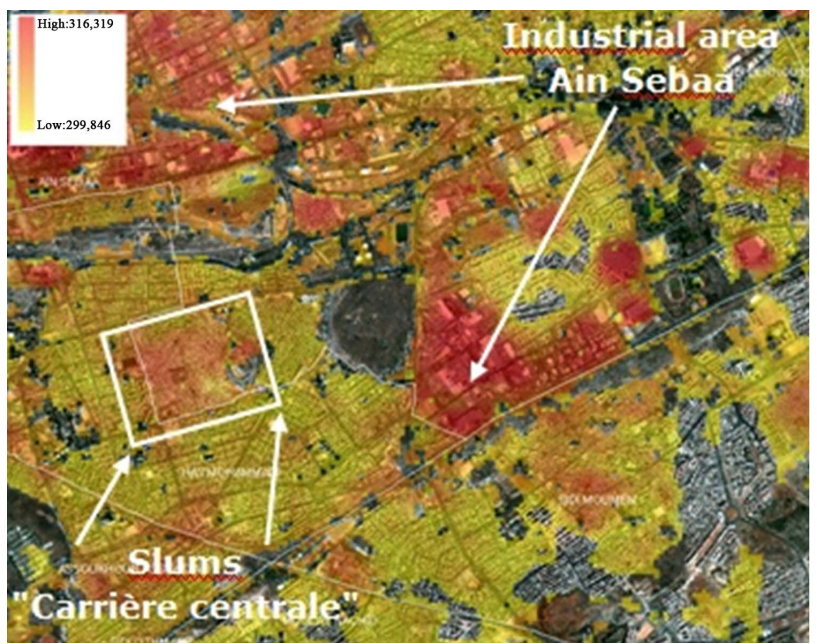

Figure 4. Formation of heat island area.

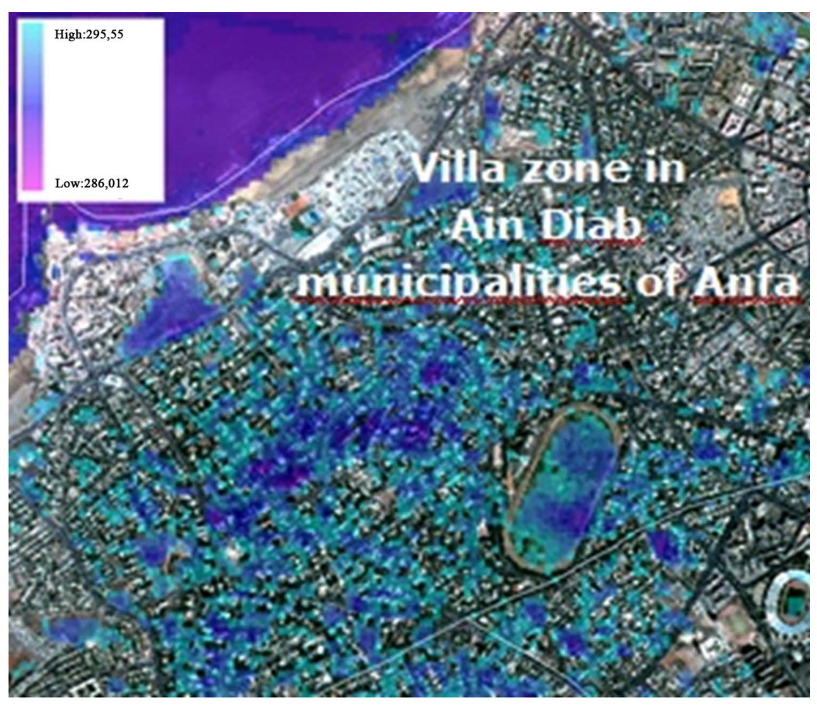

Figure 5. Fresh urban area.

This result may be more accentuated with the presence of statistical data that contains information about the number of planning per $\mathrm{Km}^{2}$ in each municipality.
It is clear that urban areas so heavily mineralized such as industrial area, parks (case of deposit containers in the port of Casablanca), the roads, parking places and the concentration of buildings contribute significantly to the phenomenon of heat islands area in the agglomeration (red color in Figure 3).

The table below (Table 3) shows the minimum and maximum temperatures, the standard deviation, the surface of heat islands in $\mathrm{Km}^{2}$, the urban surface fresh in $\mathrm{km}^{2}$ and the surface vegetation cover for each municipality in Casablanca City.

To identify the plant cover we have adopted two different segmentation methods, each method is reliable in a given environment. In urban areas the method of "Zhang" based on calculating the arithmetic mean and standard deviation gives more credibility, while the conventional segmentation method relied on the arbitrary choice of training areas is the most assigned in suburban areas.

\section{Regression Analysis between Surface Fresh and the Vegetation Cover}

To establish a correlation between urban surfaces fresh and plant covers, a regression analysis was performed, this type of analysis is the proper way to understand the characteristics listed in Table 3.

This correlation study showed that there is a strong correlation between these two variables with a correlation coefficient of 0.911 . This explains the role of the abundance of vegetation in the cooling of the urban area and thus the fight against the phenomenon of heat islands. (See Figure 6)

\section{Conclusions}

The formation of the heat islands is a fatal phenomenon that threatens the future of Moroccan agglomeration and in particular the economic metropolis, Casablanca city. The identification of areas affected by this fact is of paramount importance to detect the thermal anomalies.

In this article we have used the remote sensing techniques to determine the thermal anomalies and the blocks of freshness that promote each municipality in the region of Casablanca. The results obtained showed that heat islands are formed in the highly mineralized areas and more intense in industrial areas, slums, the concentrations of buildings and places of parking that have a characteristic similar to a black body. However, we can exploit the results of this study and mapping of slums in the city of Casablanca [17] to better understand the phenomenon of informal urbanization in the city.

Several causes explain the appearance of the heat islands in these areas, among these causes we have the thermal properties of materials: the materials used in infrastructure are low reflecting sunlight with a low albedo, and this explains why these materials absorb heat when 
Table 3. Statistical results obtained from the segmentation method.

\begin{tabular}{|c|c|c|c|c|c|c|c|c|}
\hline & Municipalities & Max_T & Min_T & Mean_T & $\begin{array}{l}\text { Standard } \\
\text { deviation }\end{array}$ & $\begin{array}{c}\text { Heat islands } \\
\text { in } \mathbf{K m}^{2}\end{array}$ & $\begin{array}{l}\text { Surface fresh } \\
\text { in } \mathbf{K m}^{\mathbf{2}}\end{array}$ & $\begin{array}{l}\text { Vegetation cover } \\
\text { in } \mathbf{K m}^{\mathbf{2}}\end{array}$ \\
\hline 1 & AIN CHOCK & 306.766 & 290.213 & 296.568 & 2.813 & 7.9587 & 6.21 & 6.6798 \\
\hline 2 & AIN HARROUDA & 310.646 & 288.709 & 295.849 & 2.907 & 4.4874 & 2.0259 & 3.2958 \\
\hline 3 & AIN SEBAA & 311.285 & 291.958 & 301.214 & 3.055 & 2.106 & 2.6154 & 2.3166 \\
\hline 4 & AL FIDA & 310.005 & 292.566 & 300.907 & 1.886 & 0.4437 & 0.4311 & 0.5337 \\
\hline 5 & ANFA & 304.795 & 291.949 & 297.599 & 2.573 & 1.6092 & 2.4165 & 1.9314 \\
\hline 6 & ASSOUKHOUR ASSAWDA & 306.111 & 292.831 & 300.695 & 2.804 & 0.6264 & 1.3635 & 1.1475 \\
\hline 7 & BEN MSICK & 303.468 & 293.562 & 300.254 & 1.973 & 0.0828 & 0.4869 & 0.4239 \\
\hline 8 & BOUSKOURA & 310.005 & 288.051 & 294.285 & 2.423 & 18.7542 & 8.4618 & 17.0289 \\
\hline 9 & DAR BOUAZZA & 309.362 & 288.709 & 296.209 & 2.654 & 19.8729 & 15.12 & 20.6118 \\
\hline 10 & EL MAARIF & 306.766 & 292.264 & 298.528 & 2.127 & 1.5867 & 2.6946 & 1.6983 \\
\hline 11 & HAY HASSANI & 304.795 & 288.83 & 297.684 & 2.689 & 3.6882 & 5.5215 & 4.8834 \\
\hline 12 & HAY MOHAMMADI & 306.111 & 294.522 & 301.231 & 1.926 & 0.5661 & 0.6201 & 0.6246 \\
\hline 13 & LAHRAOUYINE & 305.454 & 288.709 & 295.611 & 3.047 & 4.0563 & 1.5606 & 2.9088 \\
\hline 14 & MECHOUAR DE CASABLANCA & 304.133 & 293.645 & 299.992 & 1.807 & 0.0495 & 0.054 & 0.0531 \\
\hline 15 & MEDIOUNA & 306.111 & 290.541 & 296.423 & 2.649 & 0.3042 & 0.3618 & 0.3672 \\
\hline 16 & MERS SULTAN & 306.766 & 293.239 & 300.984 & 1.963 & 0.3213 & 0.4617 & 0.5166 \\
\hline 17 & MOULAY RACHID & 304.795 & 291.611 & 298.982 & 2.109 & 0.7272 & 1.1331 & 1.0431 \\
\hline 18 & NOUACEUR & 308.069 & 286.697 & 294.835 & 2.602 & 7.5042 & 3.9744 & 7.0956 \\
\hline 19 & SBATA & 308.069 & 292.19 & 297.555 & 3.039 & 1.2069 & 1.4832 & 1.5192 \\
\hline 20 & SIDI BELYOUT & 307.419 & 291.958 & 300.582 & 2.708 & 1.5525 & 1.0917 & 1.1232 \\
\hline 21 & SIDI BERNOUSSI & 309.362 & 292.279 & 300.353 & 3.236 & 2.3553 & 2.0151 & 2.1906 \\
\hline 22 & SIDI MOUMEN & 308.716 & 291.001 & 297.887 & 3.266 & 3.4038 & 4.5585 & 4.4721 \\
\hline 23 & SIDI OTHMANE & 306.766 & 292.373 & 299.179 & 2.681 & 0.5751 & 1.2942 & 1.0998 \\
\hline 24 & TIT MELLIL & 303.468 & 290.206 & 294.559 & 2.261 & 1.422 & 0.9684 & 1.4067 \\
\hline
\end{tabular}

Correlation graph

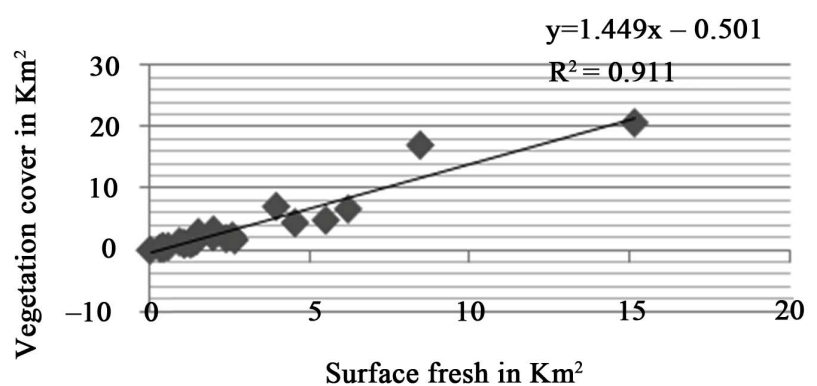

Figure 6. Correlation graph between vegetation cover and the surface fresh.

they are exposed to sunlight. Other causes shall enter into issues such as the morphology of the city which refers to the three-dimensional shape, urban development at the expense of green space that have an important role in the loss of the humidity and the loss of water available for vegetation, this will cause a decrease in evaporation in the city. In addition, other anthropogenic sources contri- bute to the emergence of heat islands in the region of $\mathrm{Ca}$ sablanca as the case of the heat generated by human activities, for example the heat generated by transport, by commercial activities and by industrial activities. This last cause anthropogenic contributes significantly to the emission of greenhouse gases, which will spoof the problem of global warming and reducing the height of annual precipitation.

All of these cases cited previously accentuates the fact that the city of Casablanca and more generally the Moroccan cities will have to face climate change, the thing that will cause detrimental problems not only to the phenomenon of global warming and the emergence of heat islands but also the appearance of the impacts that threaten the Moroccan cities such as floods, decrease in water resources and coastal vulnerability.

Moreover, the aggravation of this fact, heat islands, can lead to a deterioration of public health and particularly older people and the worsening of some diseases that already exist such as cardiovascular, neurological and respiratory diseases and sometimes it can even lead to heat 
stroke citing the case the heat wave in France that has caused more than 15,000 deaths.

It appears clear therefore that it is very important to fight against the phenomenon of formation of urban heat islands and think prospectively in 2030 and even up beyond to adapt the cities to climate change.

Ecologically the greening of the city and the creation of woodlands are the principal techniques for mitigating this fact and they contribute greatly to the reduction of harmful problems associated to public health. We have proved in this study the impact of vegetation on the cooling of urban surfaces and according to the regression analysis the correlation coefficient was 0.911 . Hence the status legislates to launch action plans and policies for a green vision contributing to fight against this phenomenon.

\section{REFERENCES}

[1] Haut-Commissariat au Plan, "Les villes Marocaines Face au Changement Climatique. Le Maroc en Perspective: Regards Croisés," Les Cahiers de l'IAU îdF, No. 154, 2010, p. 87.

[2] J. Zhang and Y. Wang, "Study of the Relationships between the Spatial Extent of Surface Urban Heat Islands and Urban Characteristic Factors Based on Landsat ETM+ Data," Sensors, Vol. 8, No. 11, 2008, pp. 7453-7468. doi: $10.3390 / \mathrm{s} 8117453$

[3] S. Gadal, "Télédétections Thermiques Infrarouges des Concentrations Urbaines au Maroc," Cybergeo: European Journal of Geography, Cartographie, Imagerie, SIG, Article 421, 2008 .

[4] A. Asmat, S. Mansor and W.-T. Hong, "Rule Based Classification for Urban Heat Island Mapping," Proceedings of the 2nd FIG Regional Conference Marrakech, Morocco, 2-5 December 2003.

[5] V. Dubreuil, C. Delahaye and A. Le Strat, "Dynamiques d'Occupation et d'Utilisation du sol et Leurs Impacts Climatiques au Mato Grosso, Brésil," Confins, No. 10, 2010, p. 16.

[6] Egis Bceom International/IAU-IDF BRGM, "Résumé Exécutif Rapport Phase 1 Maroc,” 2005.

[7] http://www.tutiempo.net/en/Climate/Casablanca/08-01-20 11/601550.htm

[8] Q. Weng, D. Lu and J. Schubring, "Estimation of Land
Surface Temperature-Vegetation Abundance Relationship for Urban Heat Island Studies," Remote Sensing of Environment, Vol. 89, No. 4, 2004, pp. 467-483. doi:10.1016/i.rse.2003.11.005

[9] W. P. du Plessis, "Linear Regression Relationships between NDVI, Vegetation and Rainfall in Etosha National Park, Namibia," Journal of Arid Environments, Vol. 42, No. 4, 1999, pp. 235-260. doi:10.1006/jare.1999.0505

[10] A. Bannari, D.-C. He, D. Morin, et al., "Analyse de l'Apport de deux Indices de Vegetation à la Classification dans les Milieux HétéRogènes," Journal Canadien de Télédétection, Vol. 24, No. 3, 1998, pp. 233-239.

[11] V. M. Griend, A. A. Owe, H. F. Vugts, G. K. Ramothw and S. W. M. Peters, "Bostswanawater ans Surface EneRgy Balance Research Program. Part 1: Integrated Approach and Field Campaign Results," BCRS Report N 91-38a, 1992.

[12] R. R. Irish, "Landsat 7 Science Data User'S Handbook," National Aeronautics and Space Administration, Report 430-15-01-003-0, 2001.

[13] Z. Qin and A. Karnieli, "A Mono-Window Algorithm for Retrieving Land Surface Temperature from Landsat TM Data and Its Application to the Israel-Egypt Border Region," International Journal of Remote Sensing, Vol. 22 , No. 18,2001 , pp. 3719-3746. doi:10.1080/01431160010006971

[14] M. Y. Bouroubi, P. Vigneault, F. Cavayas and N. Tremblay, "Le Progiciel 'Reflect' Pour la Correction Atmosphérique d'Images Satellites: Validation sur la Montéregie, Québec," Télédétection, 2006, Vol. 6, No. 1, pp. $1-8$

[15] J. Zhang, Y. Wang and Z. Wang, "Change Analysis of Land Surface Temperature Based on Robust Statistics in the Estuarine Area of Pearl River (China) from 1990 to 2000 by Landsat TM/ETM+ Data," International Journal of Remote Sensing, Vol. 28, No. 10, 2007, pp. 2383-2390.

[16] J. Zhang, Y. Li and Y. Wang, "Monitoring the Urban Heat Island and the Spatial Expansion: Using Thermal Remote Sensing Image of ETM+ Band6," Proceedings of the SPIE, Vol. 6752, 2007, p. 67522F. doi: $10.1117 / 12.760725$

[17] H. Rhinane, A. Hilali, A. Berrada and M. Hakdaoui, "Detecting Slums from SPOT Data in Casablanca Morocco Using an Object Based Approach," Journal of Geographic Information System, Vol. 3, No. 3, 2011, pp. 209216. 